\title{
Erratum to: Bio-transfer factors and temporal variation of heavy metals in different sexes of 3 species of edible brackish water fish
}

\author{
Ranil Kavindra Asela Kularatne ${ }^{1}$. Jalaldeen Mohamed Harris ${ }^{2}$. \\ Periyathamby Vinobaba $^{2} \cdot$ Champika Ellawala Kankanamge $^{3}$
}

Published online: 8 July 2017

(C) Springer-Verlag GmbH Germany 2017

Erratum to: Environ Sci Pollut Res

DOI:10.1007/s11356-017-9407-5

The original publication of this paper contains a mistake. The equation to calculate the bio-transfer factor of a metal should be read as follows (i.e., the concentration of the metal in fish needs to be divided by the concentration of the metal in water to calculate the bio-transfer factor).

Bio-transfer factor $=$ concentration of the metal in fish/concentration of the metal in water

The authors regret for the errors.

The online version of the original article can be found at doi:10.1007/ s11356-017-9407-5

Ranil Kavindra Asela Kularatne

RanilKularatne@yahoo.com.au

1 Kularatne Associates, No. 16, Samudra Sanna Road, Mount Lavinia, Sri Lanka

2 Department of Zoology, Eastern University, Vantharumoolai, Chenkalady, Sri Lanka

3 Department of Civil and Environmental Engineering, University of Ruhuna, Hapugala, Galle, Sri Lanka 